\title{
O PRIMEIRO HOSPITAL DO “SERTÃO” E A "CORRIDA DO OURO" (*).
}

\author{
LAIMA MESGRAVIS \\ Do Departamento de História da Faculdade de Filo- \\ sofia, Letras e Ciências Humanas da Universidade de
} São Paulo.

Existe um capitulo quase desconhecido da nossa história e que até hoje pouco mereceu as atenções dos historiadores ficando entregue a amadores esforçados mas sem base científica. Refiro-me ao estudo de Instituições como as Ordens religiosas, de Irmandades, das organizações de assistência social e da própria Igreja, que até hoje foram apenas examinadas mais do ponto de vista apologético ou depreciativo.

No entanto, é preciso destacar pesquisas pioneiras como: as de Taunay a respeito da Abadia de São Paulo; as de Serafim Leite sobre a Companhia de Jesus; e mais recentemente as de Sônia Aparecida Siqueira sobre a Inquisição.

Parece-nos que já é tempo de estudar as instituições citadas, de indiscutivel origem européia, que foram implantadas como uma superestrutura do processo colonizador, mas que se enraizaram, profundamente, na sociedade da colônia.

Talvez, no momento, não seja possível chegar a conclusões definitivas sobre seu funcionamento e ação, devido às grandes áreas, ainda obscuras, da nossa história econômica, social e cultural, onde os conhecimentos ainda são vagos e discutíveis.

Como exemplo lembramos a história social de São Paulo, ainda tão pouco conhecida, apesar das valiosas contribuições de Alcantara Machado, Sérgio Buarque de Holanda, A. E. Taunay, Alfredo Ellis

(*) . - Comunicação apresentada na $2^{\text {a }}$ Sessão de Estudos, no dia 6 de julho de 1972 aNota da Redação). 
Jr. e outros .Isto nos impede de compreender a mentalidade do paulista e, por conseguinte, suas motivações, valores e ações que presidiam o apoio ou descaso no que se refere às instituições de caráter assistencial.

O estudo de instituições necessita, portanto, para conclusões sólidas e fundamentadas de um conhecimento profundo da vida econômica, social e cultural, do meio em que vivem e agem.

Apesar das deficiências já citadas, da falta de trabalhos de apoic, é com objetivo de mostrar os estreitos laços entre o meio social e econômico e a vida das instituições que estudamos este momento da história de São Paulo.

No dia 17 de dezembro de 1714 , em sessãó de Mesa, o provedor da Irmandade da Santa Casa de. Misericórdia, Isidro Tinoco de Sá apresentava uma sugestão de alcance histórico no que se refere a assistência médica e social do Brasil Colonial.| Deixemos que o primeiro e único documento histórico, que descreve o início do projeto, do qual resultaria a criação do primeiro hospital de São Paulo, fale por si:

"Termo da primeira mesa que faz o Irmão Provedor Izidro Tinoco de Saa".

"aos trinta ehum dias do mez de Dezembro de mil e setecentos e catorze annos nesta Santa Casa de Miz.a e no consistorio della estando junto o Irmão Provedor e mais Irmãos da Meza p. a se tratar do que pertencia a esta $\mathrm{St}^{\mathrm{a}}$ Cazae aum.to della eseasentou. q. sedesse principio ao hospital e se recolhece nelle hua mulher pobre com sua filha tão bem enferma $q$. fizera petição ese apresentarão duas petições de horfãs $p^{a}$ se cazarem em dia de $S^{a}$ Izabel ambas filhas de Irmãos, e se despacharão nove petições depobres a oito patacas cada hua. Feito em Meza ao dito dia mes e anno. Franco. Cardoso Sodré o escrevi por auzencia do Escrivão" (1).

Era o primeiro hospital que se construia no chamado "sertâo", isto é, no interior, fora das cidades portuárias da estreita faixa litorânea que abrigava a maior parte da população. Até então os hospitais construidos visavam, sobretudo, socorrer as tripulações de navios e os colonos recém-chegados das longas e estafantes viagens da Europa e da India.

(1). - Livro de deliberações de Meza da Santa Casa de Misericordia de São Paulo de 1703 a 1730 (I). Arquivo da Provedoria, fôlha 60v. 
Esses elementos recém-chegados, ou de passagem, não encontravam socorros de instituições públicas e estavam fora do amparo dos laços de solidariedade da sociedade patriarcal.

Foi para solucionar este grave problema, que desde o início da colonização, o governo português incentivou a criação de Irmandades da Santa Casa de Misericórdia, que através da iniciativa privada, dava a assistência social, sem onus para o erário.

A confraria, formada por leigos, geralmente, socorria os doentes e indigentes ;abrigava os órfãos; dotava as moças e amparava os presidiários. Surgira em Portugal em 1498, sob a égide de D. Leonor, viúva de D. João II, e irmã de D. Manuel, que na época exercia a regência. D. Manuel, percebendo as possibilidades da instituição, deuthe a proteção real, o que ajudou sua rápida expansão pelo reino e colonias. Onde havia portugueses, havia a Santa Casa. A importância da confraria foi bem definida pelo historiador inglês Russel-Wood, que em recente trabalho, afirma

"from the detailed history of the Misericordia of Bahia and the general references to the principal branches in Africa and Asia. it is clear that the Portuguese crown, local governors or viceroys, and city councils realied Heavily on individual organisation to provide social aid" (2).

O primeiro hospital da Irmandade da Santa Casa de Misericórdia do Brasil foi fundado por Brás Cubas, em 1543, na vila de aSntos; seguiram-se o do' Salvador em 1449; e depois os de Vitória, Olinda e Rio de Janeiro.

Embora a primeira notícia documentada da existência de hospital em São Paulo seja a já transcrita, a Irmandade já devia existir desde os últimos anos do século XVI. Assim țemos a referência bastante vaga do testamento de Isabel Fernandes, de 1599, que diz:

"Deixo à Misercórdia mil réis" (3)

sem especificar se se trata de Irmandade existente em São Paulo, ou da mais antiga, de Santos. Por referência da Ata da Câmara de São

(2). - A. J. R. Russel-Wood, Fidalgos and Philanthropists The Santa Casa da Misericordia of Bahia 1550-1753. University of California Press, 1968.

(3). - Inventários e Testamentos. Vol. I, pg. 256, São Paulo, 1920. 
Paulo, de 17 de agosto de 1608 , sabemos que a Irmandade possuia pelo menos uma igreja que servia de matriz à vila (4).

A existência da Irmandade com Igreja própria não implica, forçosamente, na presença de hospital, que por ser um edifício de manutenção cara só iria surgir quando as condições locais exigiam.

Durante o século XVII a diśpersividade do núcleo paulistano; aliado às estreitas ligações familiares e ao sistema de amparo proporcionado aos elementos menos favorecidos, que formavam a classe dos agregados, dentro da organização patriarcal, não houvesse necessidade de um hospital. Mesmo os raros visitantes ou novos colonos podiam ser absorvidos pela sociedade local.

A pobreża do planalto, onde as atividades econômicas se resumiam na agricultura de subsistência e na caça ao índio, é bem visível nos inventários e testamentos, tão bem aproveitados por Alcântara Machado, e nas Atas e Registros da Câmara Municipal, além dos relatos dos cronistas, dão bem a idéia da modéstia das construções locais.

Isso explica a escassa atividade da Irmandade, que, nesse período limitou-se a enterrar os mortos, a distribuir algumas esmolas aos pobres e a dotar órfãos.

\section{$A$ "corrida do ouro" e seus efeitos.}

A descoberta do ouro, em diversas regiões de Minas Gerais na década de 1694-1704, provocou a primeira "corrida de ouro" da História, esvaziando as vilas do planalto, o Rio de Janeiro, as cidades e engenhos do Nordeste e atraindo aventureiros de toda sorte, de Portugal e do resto da Europa.

A melhor de crição desta convulsão social é a de Antonil cujas páginas antológicas transcrevemos:

"A sede insaciavel do ouro estimulou a tantos a deixarem suas terras e a meterem-se por caminhos tão ásperos como são os das minas, que dificultosamente se poderá dar conta do número das, pessoas que atualmente lá estão. Contudo, os que assistiram nelas nestes últimos anos por largo tempo, e as correram todas, dizem que mais de trinta mil almas se ocupam, umas em catar, e outras em mandar catar nos ribeiros do ouro, e outras em nego.

(4) :- Atas da Câmara da Vila de São Paulo. Vol. II. Arquivo do Estado. 
ciar, vendendo e comprando o que se há mister não só para a vida. mas para o regalo, mais que nos portos do mar.

Cada ano, vêm das frotas quantidade de portugueses e de estrangeiros, para passarem às minas. Das cidades, vilas, recôncavos e sertões do Brasil, vão brancos, pardos e pretos e muitos índios de que os praulistas se servem. A mistura é de toda condição de pessoas; homens e mulheres, moços e velhos, pobres e ricos, nobres e plebeus, seculares e clérigos, e religiosos de diversos institutos, muitos dos quais não tem no Brasil convento nem casa" ( 5 ..

\section{Segundo Boxer}

jamais coisa assim fora vista e jamais tornou a ser vista até que surgisse a "corrida do ouro" na Califórnia em 1849" (6).

Também os documentos oficiais revelam os problemas causados por este êxodo incontrolável como conta D. Álvaro da Siqueira Albuquerque, governador da Repartição Sul, em carta de 5 de maio de 1704, ao governador da Bahia:

“. . . Eu cada dia me acho mais só, assim de soldados como de moradores, porque o excesso com que fogem para as minas nos dá a entender que brevemente ficaremos sem ninguem. Também suponho que V. S. assim o experimenta, porque das Minas me escreve o Cônego Gaspar Ribeiro que be tanto o excesso de gente que entra pelo sertão da Bahia que brevemente entende se despovoará essa terra . . . (7).

A miragem do ouro provocou a deserção de soldados e marínheiros ameaçando a defesa da costa e desorganizando o transporte marítimo. A respeito reiterava, em 8 de julho de 1704, o Governador do Rio de Janeiro, D. Fernando Martins Mascarenhas de Lencastre, em carta a Miguel Teles da Costa, ordens anteriores:

"Por várias vezes tenho escrito a V. Mce. sobre que não deixe passar ninguem, digo, pessoa alguã para as minas, sem que mostre licença minha na forma de ordem de S. Mage. que Ds.

(5). - João Antônio Andreoni (Antonil), Cultura e Opulência do Brasil, pgs. 263 e 264, São Paulo, 1967. 1963.

(6) : - C. R. Boxer, $A^{-I}$ Idade de Ouro do Brasil, pg. 58, São Paulo,

(7) . - Ms. do Arquivo Nacional - Coleção Governadores do Rio de Janeiro. Livro XIII-A, f. $273 \mathrm{v}$, citado por Mafalda Zemela in $O$ abastecimenot da Capitania de Minas Gerais no século XVIII, pg. 40, São Paulo, 1951: 
guarde e como acho que se não guarda o que tenho mandado, pois me constão vão nuytas pessoas sem a dita licença e passão tambem muytos soldados, artilheyros, marinheyros e outras pessoas de todas as embarcações, navios e guarda-costas dei conta deste particular ao dito Sr. pelo grande prejuizo que se segue a esta Capitania" (11).

As restrições impostas não impediram o fluxo constante de aventureiros de toda sorte em direção do Eldorado, chegando a ameaçar de despovoamento regiões de Portugal, como o Minho, conforme assinala a lei de 20 de março de 1720 , que reitera proibições anteriores de 1709 e 1711 e restringe a permissão de ida aos funcionários nomeados com seus criados, que, aliás, deveriam ser portugueses (9).

Esse afluxo repentino de milhares de mineradores provocou, como é sabido, terríveis crises alimentares, com a morte por inanição de centenas de infelizes que haviam se lançado na aventura, sem recursos, para esta região inculta e onde de início, nada se produzia.

Aos núcleos de povoamento mais próximos coube a tarefa de alimentar os mineradores e, naturalmente, o primeiro a sofrer o impacto das novas exigências foi São Paulo, seguido pelō Rio de Janeiro e Bahia.

E' bastante conhecido o fato de que a população dos núcleos urbanos do Brasil Colonial, com exceção das classes abastadas, sempre sofreu de subnutrição crônica, devido aos sistemas da produção monocultora voltada para a exportação conforme ressalta Caio Prado Jr. (10) .

Talvez a única exceção fosse a das vilas do planalto de Piratininga, devido ao sistema de policultura aqui vigente, mas que nesta conjuntura foram as primeiras a sofrer as consequências da "corrida do ouro". Em primeiro lugar porque grande parte de seus habitantes correu para as Minas, fose para minerar, fosse para comerciar; em segundo lugar, com este despovoamento e consequente abandono das roças, a produção local diminuiu; finalmente a violenta elevaçăo dos preços de todos produtos agrícolas e artesanais, que encontravam um mercado mais compensador nas Minas, atingiu seus moradores e os forasteiros em trânsito.

(8). - Ibidem. Livro XIII-A, fls. 332v, citado M. Zemela, op. cit., pg. 41. Janeiro

(9). - Anais da Biblioteca Nacional. Vol. XXVIII, pg. 145, Rio de

(10) . - Caio Prado Jr., História Econômica do Brasil, pg. 43, São Paulo, 1959 . 
As atas da Câmara de São Paulo trazem constantes referências e providências a respeito da carestia, como a de 1704 que se refere aos preços abusivos do milho, feijão e farinha de guerra (11) e a de 1705 que lamenta a miséria da população (12).

Muitos habitantes do planalto preferiram, então, à mineração, aumentar suas lavouras na região Oeste (Bragança, Atibaia, Jundiaí, Campinas) para produzir para o novo mercado que surgia. Outros, com o mesmo fim, criavam gado nos Campos Gerais de Curitiba, para depois expandir-se até o Rio Grande do Sul, ou ainda estabeleceram-se nos sertões baianos (13).

Com o êxodo de paulista que partiam para as Minas, fúndavam novos núcleos de povoamento com a agricultura e a criação de gado, a vila de Piratininga ficou entregue a forasteiros que chegavam, muitas vezes, totalmente desprovidos de recursos, também em busca de ouro.

A vila sofreu um processo de ascensão político-administrativa como recultado dos violentos incidentes entre paulistas e emboabas pela posse das Minas. Assim a 3 de novembro de 1709, a carta régia criava a Capitania de São Paulo e Minas para que o novo governador nomeado Antônio de Albuquerque Coelho, pudesse conciliar melhor os interesses em jogo e administrar a tumultuosa região. Dois anos depois, a 24 de julho de 1711 nova carta régia, elevava a vila de São Paulo à condição de Cidade, a pedido de seus cidadãos, que solicitaram ainda a criação de um bispado, alegando os relevantes serviços que haviam prestado à Coroa (14).

Estas transformações administrativas aumentaram o número de funcionários burocráticos e, sobretudo, de soldados da guarda do governador e portanto, de elementos alienígenas à sociedade local.

Mudava, assim, a composição da população e da sociedade com o aparecimento de um grande número de indivíduos que não tinham laços de parentesco ou clientela com os antigos habitantes e que nas suas aflições e doenças necessitavam do amparo de uma instituição pública de caráter 'urbano. E' que São Paulo, 'boca de Sertão”, ago-

(11). - Atas da Câmara Municipal da Vila de São Paulo. Vol. VIII, pg. 76 .

(12). - Ibidem. Vol. VIII, pg. 96

(13). - Informaçôes sobre as minas do Brasil, Ms. anônimo in "Anais da Biblioteca Nacional", vol. LVII, pg. 172.

(14) . - Affonso de E. Tanay, História da Villa de São Paulo no século XVIII (1701-1711), pgs. 161-162. São Paulo, 1931. 
ra encontrava-se na situação de porto ao qual arrỉbavam aventureiros de todas as partes.

Era preciso acudir a estes problemas e era natural, que a Misericórdia da qual faziam parte, muitos paulistas enriquecidos nas Minas como por exemplo

"José de Góis e Morais, o mesmo que chegou a negociar con o marquês de Cascais a compra da Capitania de São Vicente, só não a completañdo porque intempestivamente interveio a Coroa chamando a si o negócio já ajustado - Matias Rodrigues da Silva e José Ramos da Silva, avô e pai do moralista Matias Aires..." (15).

Os 2 primeiros constam da lista de irmãos que assinaram o termo de mesa de 24 de abril de 1715 na qual foi decidida a construção do Hospital, e foram provedores da Irmandade. Matias Rodrigues da Silva exerceu a provedoria no ano compromissal 1704-1705, enquanto qua José de Góis e Morais o fez de 1722 a 1723 (16).

\section{A construção do hospital.}

O projeto de construção de um hospital aventado em dezembro de 1714 teve continuidade por decisão de mesa de 24 de abril de 1715 , que decidiu curar nele aqueles que não pudessem ser atendidos em suas casas (17).

Para a construção e manutenção do mesmo seriam usados os rendimentos das "tumbas" (enterros pagos), as jóias dos irmãos e as doações. Organizava-se a administração do hospital indicando dois irmãos para fiscalizarem o cuidado dos doentes pelos médicos, cirurgiões, sangradores e enfermeiros. Os próprios irmãos de mesa deveriam fornecer, em rodízio, a alimentação dos doentes enquanto não houvesse recursos suficientes.

(15). - Sérgio Buarque de Hollanda, Movimentos de População em São Paulo no século XVII, pg. 106, in "Revista do Instituto de Estudos Brasileiros" nợ 1, São Paulo, 1966.

(16). - Suely Robles Reis de Queiroz, José de Góis e Morais: o paulista que quase comprou. São Paulo, in "Revista de História" no 86, São Paulo, 1971. As pesquisas da autora comprovam que José Góis e Morais, enriquecido nas minas, tentou comprar parte da Capitania de Santo Amaro, em 1708; foi capitão-mor da vila em 1711; guarda-mor das minas de Paranapanema em 1718 e criador de gado nos Campos Gerais.

(17). - Livros de deliberações de Meza da Santa Casa de Misericordia de São Paulo de 1703-1730 (I), f. 60v. 
O Registro Geral da Câmara Municipal de São Paulo revela que a 4 de julho de 1716 a Santa Casa recebeu uma "carta de Data de chãos" devolutos para a construção de igreja e hospital (18).

$\mathrm{Na}$ "carta de data" não consta a localização mas no Registro da mesma existe a referência a

"uns chãos com muita largueza". defronte ao paço do defunto Pedro Jâcome" (19).

Nos livros de Atas dos termos de Mesa só encontramos novas referências de 3 de julho de 1717 , de difícil leitura, na qual consta que se ajustou por novecentos mil réis com o capitão Pedro Frz. a construção de igreja, sacristia, corredor e hospital (20).

Pelo menos parcialmente a construção foi completada conforme se pode concluir por um

"quartel sobre as limpas desta cidade e chãos dos trez meses", passado a 11 de abril de 1718 , que tratando da limpeza da cidade mandava ". . . botar somente os ciscos, ou lixos nos covões da Misercória” (21).

Mas as dificuldades financeiras eram enormes, conforme se pode deduzir de verbete do Catálogo de documentos sobre a história de Sãu. Paulo do Arquivo Histórico Ultramarino de Lisboa que trata de uma representação de 26 de julho' de 1729 , em que a Irmandade pede auxílio (22). Sobre esta representação recairam dois despachos do Conselho Ultramarino pedindo informações ao governador de São Paulo. Outro verbete do referido Catálogo resume a carta do governador Antônio da Silva Caldeira Pimentel que ao assumir o cargo encontrou a Santa Casa em estado tão deplorável que ruiu e trata da reedificação promovida pelo provedor Manuel Luís Ferraz (23).

(18). - Registro Geral da Câmara Municipal de São Paulo 1710-1734. Vol. IV, pg. 211, São Paulo, 1917.

(19). - Ibidem, pg. 210.

(20). - Livro de deliberações, f. 66v .

(21). - Registro Geral da Câmara Municipal de São Paulo 1710-1734. Vol. IV, pgs. 340-341, São Paulo, 1917.

(22). - Revista do Instituto Histórico e Geográfico Brasileiro, tomo especial, II, pg. 53 .

(23). - Affonso de E. Taunay, História da Cidade de São Paulo no sérulo XVIII. $2^{\circ}$ tomo, pgs. 6 e 184. São Paulo, 1934. - Ferraz foi personagem de importância na capitania, negociante abastado, arrematador dos dizimos de Cuiabá; procurador da Câmara em 1722; encarregado, em 1728, com mais três moradores, de cobrar o donativo dos Dotes dos Príncipes (São Paulo deveria contribuir com 4 contos anuais). 
No volume I da coleção dos Documentos Históricos na página 219 e seguintes, anexo a novo pedido de informações sobre a situação da Misericórdia, datado de 3 de julho de 1733, encontramos uma cópia da carta da mesa da Irmandade de 1729, que passamos a transcrever:

\footnotetext{
"Senhor

Já no passado expuzemos a Vossa Magestade o estado desta Santa Casa da Misericória por ir sempre a menos e esta diminuição ser a cauza do pouco fervor e vontade de se augmentar a Irmandade, e chegando a mesma Igreja a padecer ruina, entrou a reedifica-la a sua custa o Provedor Manuel Luis Ferraz e acabado o seu anno, mas não a obra, que depende de mais tempo saiu outra vez este anno, eleito por Provedor e continua a mesma obra com excessivo gasto, sem chegar, ainda à fabrica do hospital que também esta toda destruida e de tudo destituida, e carece de edificar-se e muito mais no tempo presente, em que se acha tanta multidão de forasteiros que concorrem a esta capitania $e$ companhta de soldados que assistem ao governador dela e sendo esta casa da Misericórdia a única qu ehá em toda a Capitania de serra acima, não tem hospital em que possam ser recolhidos e curados.

Com tôdas estas necessidades pedimos a Vossa Magestade a esmola de ajuda de custo para as referidas obras aplicadas nos rendimeintos dos quintos ou dizimos desta mesma capitania, e suas minas o que esperamos na grandeza real de Vossa Magestade como tã opio e magnifico.

Escrita em mesa da Santa Casa de Mizericordia desta cidade de São Paulo aos 26 de julho de 1729//Manuel Luis Ferraz//Miguel Alves Ferreira//João Vieira Fagundes//João Batista de Carvalho, thesoureiro dos Irmãos da Santa Casa de Misericordia de São Paulo".
}

A década que se iniciou em 1720 foi fertil em acontecimentos dramáticos e ruinosos para São Paulo. Em 1719 Pascoal Moreira Cabral descobriu o ouro de Mato Grosso, provocando, no ano seguinte, nova "corrida de ouro", que chegou a despovoar a cidade de São Paulo, Rio de Janeiro e Minas Gerais. No fim do mesmo ano, mais precisamente em 2 de dezembro de 1720, a região de Minas Gerais era separada da capitania de São Paulo (que ia de Angra dos Reis até Laguna), passando a ter governo próprio. Cinco anos depois, Bartolomeu Bueno da Silva descobria as jazidas de Goiás, repetindo pela terceira vez o fenômeno do êxodo da população. 
A necessidade de defender a região das novas minas, próxima dos domínios castelhanos, resultou no acantonamento de uma companhia de soldados na cidade a que se refere a carta do governador Manuel Luís Ferraz.

Apesar do patético apelo à Coroa nenhum auxílio parece ter sido prestado, porque a obra de reconstrução encetada por Ferraz ficou no edifício da Igreja que, entretanto, só se completou na década de 1740. O hospital não foi reconstruido e em sessão de Mesa de 11 de fevereiro de 1742 foi decidida a compra de 4 casas contíguas à Igreja para nelas serem abrigados os doentes. A compra só foi efetivada por escritura de 21 de janeiro de 1744, como consta de Livro de Notas do Tabelião Damaso Álvares de Abreu, pela quantia de 6 mil cruzados do coronel Manuel Antunes Batista de Andrade. Entretanto, as casas só foram convertidas em hospital durante a provedo. ria de Miguel Alves Ferreira, em 1749 (24).

A demora da aquisição e montagem do novo hospital deve-se com certeza às dificuldades financeiras da Irmandade que a levaram a enviar nova petição, em 1752 , pedindo auxílio para a Instituiçạa, por meio de seu procurador em Lisboa, o jesuita Pe. Domingos de Sousa. A resposta demorou e resumiu-se em pedido de informações ao ouvidor geral João de oSuza Filgueiras sobre a situação da Irmandade. Filgueiras alegou dificuldades para consegui-la sdevido à deficiência da documentação da Santa Casa e a ausência de membros de mesas anteriores que se encontravam em Cuiabá e Goiás (25).

\section{A decadência do hospital.}

São Paulo atravessava a fase mais negra de sua história, com o desmembramento resultante da criação das capitanias de Goiás e Mato Grosso em 1748 e até a perda da autonomia no mesmo ano, ficando subordinada ao Rio de Janeiro. Para Raul de Andrada e Silva

"a ascensão administrativa coincidira durante o setecentismo, uma fase de decadencia econômica e de estagnação ubana" (26).

(24). - Francisco Martins de Almeida, Primeiro Relatório sôbre a a $S_{n-}$ ta Casa de Misericórdia da Cidade de São Paulo - 1875. 2a edição, São Paulo, 1909, pgs. 21 e 22 .

(25). - (Ver pg. seguinte).

(26). - Raul de Andrada e Silva, Odilon Nogueira de Matos e Pasquale Petrone - A evolução urbana de Säo Paulo, pg. 25, vol. V, Coleção da "Revista de História", São Paulo, 1955. 
A "corrida do ouro" que dispersara seus habitantes mais ativos pelas regiões auríferas de Minas Gerais, Mato Grosso e Goiás; pelas áreas abastecedoras do interior da própria capitania, da Bahia, dos campos de Curitiba e do Rio Grande, deixara a cidade para os forasteiros: aventureiros, comerciantes, burocratas e soldados. A pobreza e o desânimo tomavam conta da população. Alguns, poucos, conseguiam lucros razoáveis com o comércio de gado muar, cavalar e bovino que traziam do Rio Grande do Sul, enquanto outros viviam de um incipiente serviço de transportes com tropas de mulas. E' possí'el que essa última atividade, caracterizada pela mobilidade constante, fosse das mais atraentes para os descendentes dos bandeirantes, facilitando a transição para a sedentarização definitiva com a agricultura. O restante vivia de uma precária agricultura de subsistência e, talvez, já se iniciasse, na região de Itu, a cultura da cana-de-açúcar, que iria tomar impulso a parir do governo do Morgado de Mateus.

Restaurada a capitania por Pombal, em 1765, o primeiro governador, o Morgado de Mateus (D. Luís Antônio de Sousa Botelho Mourão tentou, através de inteligentes medidas administrativas, reerguer a economia local.

Os esforços, que visavam estimular a agricultura, foram prejudicados pelos recrutamentos constantes para as guerras contra os castelhanos no Sul e o desastrado projeto de Iguatemi.

Em carta de 1767, citada por Ernani da Silva Bruno, o morgado de Mateus referindo-se aos seus esforços de atrair os paulistas para a vida militar dizia:

“. . . consegui diminuir-lhes o horror do nome de soldados, facilitei-lhes as comodidades desta profissão, fiz-lhes ver a estimaçắo e a honra dela, e consegui levantar seis corpos de milícias, quatro de infantaria e dois de cavalaria . . ." (27).

No que se refere a Misericórdia o Morgado de Mateus ocupouse com a restauração da Irmandade (28) e providenciou a reconstrução do hospital (29) pedindo auxílio para o transporte de pedras para esse fim (30).

(25) . - Raul Votta, A Irmandade da Santa Casa de São Paulo in "Boletim". Vol. II, pgs. 127 a 131, São Paulo, 1951.

(27). - Ernani da. Silva Bruno, História e Tradiçães da Cidade de São Paulo". Vol. I, pg. 87, Rio de Janeiro, 1954.

(28). - Documentos Interessantes para a História e Costumes de São Paulo, vol. XXIII, pg. 145 .

(29). - lbidem. Vol. LXIV, pg. 94.

(30). - Ibidem. Vol. XXXIII, pg. 99. 
Apesar de evidente má vontade com que seu sucessor Martim Lopes Lobo de Saldanha refere-se ao Morgado, estes esforços parecem ter fracassado, tanto que em 30 de agosto de 1775 duas das casas foram alugadas à Câmara para servirem de aldeia por 800 réis mensais (31).

Quanto às outras duas estariam, segundo o relatório de Francisco Martins de Almeida, servindo, desde 1744, como enfermaria dos Regimentos de Mexia e Voluntários (32).

A Santa Casa só obteve a restituição das suas propriedades em 1801, depois de completada a construção do Hospital Militar pelo governador da capitania e então provedor da Misericórdia, Antônio Manuel de Melo e Castro Mendonça.

Os doentes pobres da Misericórdia passaram a ser ali atendidos mediante pagamento de diárias pela Irmandade, que assim poupava as despesas de manutenção de outro hospital, o que seria impos ível nas suas condições financeiras. A Irmandade só começou um verdadeiro processo de reerguimento durante o governo de Franca e Horta que coincidiu com a chegada da Família Real, e sobretudo, logo após a Independência.

Dadas as condições econômicas, sociais e culturais da capitania, como de toda colônia, é de se supor que o tratamento dos doentes fosse bastante precário. O levantamento feito nos documentos coloniais do século XVI ao XVIII, só revela a existência ocasional de alguns cirurgiões e médicos na capitania, que além do mais, pouco permaneciam, partindo para outras plagas em busca de melhores condições de trabalhọ.

O curativo dos doentes era feito, geralmente, por "curandeiros" e barbeiros "sangradores".

Diante do exposto é de se supor que a assistência do hospital da Santa Casa se dirigisse, sobretudo, no sentido de proporcionar abrigo e alimento. No que se refere a medicação, ela deve ser dividida em duas categorias; a de origem européia e a local, de inspiração indígena.

A européia baseava sua terapêutica em repouso, dietas, purgativos, eméticos e sobretudo, nas sangrias, que eram tidas como uma

(31). - Atas da Câmara Municipal de São Paulo 1771-1776. Vol. XVI, pgs. 23 .

(32). - Francisco Martins de Almeida, op. cit., pg. 22. 
panacéia universal para todos males. Quanto à local, além de empregar os métodos europeus, recorria à vasta farmacopéia indígena com suas ervas e essencias, às quais se acrescentava geralmente, o tabaco e a cachaça.

Devido ao desaparecimento da maior parte da documentação da Irmandade e da inexistência de outras fontes nada mais é possível acrescentar sobre o funcionamento do primeiro hospital de São Paulo. Por não se enquadrarem nos objetivos deste trabalho deixamos de examinar as outras modalidades de assistência da Irmandade da Santa Casa da Misericórdia que abrangiam ainda a concessão de esmolas, de dotes para órfãos e dos enterros, que eram gratuitos para indigentes e escravos.

Conclusão.

O primeiro hospital do hinterland brasileiro, fundado em 1717, em São Paulo, para atender aos problemas médicos e assistenciais criados pela "corrida do ouro", surgiu justamente quando esta cidade transformou-se numa espécie de "porto" do "sertão" onde se detinham todos os recém-chegados. As transformações administrativas que expandiram as funções do núcleo urbano paulista agravaram os problemas locais, sem que as autoridades coloniais se interessassem por solucioná-los, ficando este encargo para a iniciativa privada. E' interessante notar, que além das bandeiras, As lrmandades da Misericórdia constituem o único tipo de asșociação para um empreendimento comum, além das atividades de defesa, que a sociedade colonial conheceu.

O funcionamento do hospital, e da Irmandade em geral, acompanhou as vicissitudes da capitania que serviu de trampolim e reserva demográfica para o povoamento de defesa do Centro-Oeste e Sul, depois de ter sido o agente da ocupação destas regiões.

O empobrecimento e desânimo que atingiram a capitania dos bandeirantes nos meados do século afetaram profundamente a Irmandade, que só deu os primeiros e tímidos sinais de reerguimento a partir do governo do Morgado de Mateus. Entretanto, somente no século XIX, com o desenvolvimento de uma economia própria, com a produção de açúcar e café para a exportação, com o consequente aumento demográfico e a intensificação do processo de urbanização, foi que a Mirericórdia pôde encetar um novo hospital e novas modalidades de assistência médica e social. Iniciou-se então a fase mais brilhante desta Instituição que se prolonga até hoje. 